\title{
Effect of temperature on structure and corrosion resistance for electroless NiWP coating
}

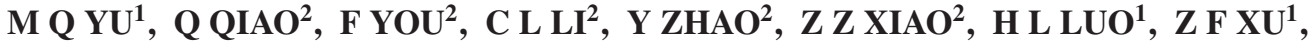 \\ KAZUHIRO MATSUGI ${ }^{1}$ and $\mathrm{J}_{\mathrm{K}} \mathrm{YU}^{2, *}$ \\ ${ }^{1}$ Graduate School of Engineering, Hiroshima University, 1-4-1 Kagamiyama, 739-8527 Higashi-Hiroshima, Japan \\ ${ }^{2}$ State Key Laboratory of Metastable Materials Science and Technology, Yanshan University, Qinhuangdao 066004, \\ Hebei, People's Republic of China
}

MS received 20 April 2015; accepted 11 November 2015

\begin{abstract}
The effect of plating temperatures between 60 and $90^{\circ} \mathrm{C}$ on structure and corrosion resistance for electroless NiWP coatings on AZ91D magnesium alloy substrate was investigated. Results show that temperature has a significant influence on the surface morphology and corrosion resistance of the NiWP alloy coating. An increase in temperature will lead to an increase in coating thickness and form a more uniform and dense NiWP coatings. Moreover, cracks were observed by SEM in coating surface and interface at the plating temperature of $90^{\circ} \mathrm{C}$. Coating corrosion resistance is highly dependent on temperature according to polarization curves. The optimum temperature is found to be $80^{\circ} \mathrm{C}$ and the possible reasons of corrosion resistance for NiWP coating have been discussed.
\end{abstract}

Keywords. AZ91D magnesium alloy; electroless NiWP coating; temperature; corrosion resistance.

\section{Introduction}

Magnesium alloys are the lightest metal structure materials in the practical application. They have been widely used in aerospace, automobile and electronic industries due to their outstanding characteristics such as high strength-to-weight ratio, high electromagnetic shielding, good damping property and mach inability [1-4]. However, the active magnesium alloys have poor corrosion resistance and thus have been limited for their further exploitation. To overcome such shortcomings, work piece surface of magnesium alloy often has to be treated. The common surface modification methods include anodic oxidation, electroplating as well as direct electroless nickel plating, etc.

It is well known that electroless plating is an effective corrosion resistance method [5-7]. In recent years, NiWP alloy coatings prepared by electroless plating have been widely used to provide some excellent properties like high corrosion resistance and wear resistance, and to obtain uniform coating thickness on the shape of complex castings [8-10]. However, it is often being distressed because of the plating solutions being acidic, which will easily damage or corrode the magnesium alloy surface. To deal with this, much work has been done and one of the prospect method is using nonacid plating solutions like nickel sulphamate solution.

Generally speaking, the substrate has to be pickled before plating treatment, that is to say, the substrate is immersed in a solution of chromate and nitric acid. And HF solution

*Author for correspondence (yujinku@ysu.edu.cn) would be used to form a conversion film before electroless nickel deposition [11-13]. However, as $\mathrm{Cr}^{6+}$ is carcinogenic substance and HF is highly toxic, their harm effect must be controlled during the pickling process.

Therefore, a new method was introduced in our work to deposit Ni-W-P alloy on the AZ91D alloy by using neutral basic nickel carbonate bath. Generally speaking, the quality of electroless plating is associated with some factors like main salt, $\mathrm{pH}$ value, time, temperature and so on. As temperature is an important parameter for thermodynamics and kinetics of chemical reaction, effect of temperature on the electroless plating of NiWP alloy has been studied in surface morphologies [14], hardness [15], wear resistance [16] and crystalline phases [17]. However, these researches are focussed on the deposited Ni-W-P alloys treated to a temperature more than $200^{\circ} \mathrm{C}$. To the best of our knowledge, the effect of plating temperature on the NiWP alloy has rarely been reported [18]. It is very significant to get a clear understanding of this knowledge both in science research and engineering application. In the present work, we have investigated in detail the effect of temperature on structure and corrosion resistance for electroless NiWP coating.

\section{Experimental}

The commercial AZ91D magnesium rolling alloy is used as the substrate. The chemical composition of the alloy can be found elsewhere [22]. Samples were prepared with sizes of $20 \times 30 \times 3 \mathrm{~mm}$. The samples are grinded with water sand paper and cleaned with acetone, and then treated by alkali washing, acid pickling, activation as well as electroless nickel 
plating. Deionized water cleaning is necessary for Ni-W-P alloy coating at each step. Alkali washing is proposed for $62 \mathrm{~g} \mathrm{l}^{-1} \mathrm{NaOH}$ and $10 \mathrm{~g} \mathrm{l}^{-1} \mathrm{Na}_{3} \mathrm{PO}_{4} \cdot 12 \mathrm{H}_{2} \mathrm{O}$ solution for $10 \mathrm{~min}$ at $60^{\circ} \mathrm{C}$, the pretreatment solution is chromate free, where $\mathrm{Zn}\left(\mathrm{H}_{2} \mathrm{PO}_{4}\right)_{2} 100 \mathrm{~g} \mathrm{l}^{-1}, \mathrm{MgSO}_{4} 10 \mathrm{~g} \mathrm{l}^{-1}$, $\mathrm{HF} 2 \mathrm{ml} \mathrm{l}^{-1}$, $\mathrm{H}_{3} \mathrm{PO}_{4} 10 \mathrm{ml} \mathrm{l}^{-1}$ and $\mathrm{HNO}_{3} 12 \mathrm{ml} \mathrm{l}^{-1}$ solution to obtain a conversion film [11].

Plating bath composition and operating parameters of NiWP alloy are listed in table 1. The electroless NiWP bath contains basic nickel carbonate as the nickel ions provider, sodium tungstate as the tungsten ions provider, sodium hypophosphite acts as a metal reducing agent and citric acid as complexion agent. An aqueous ammonia bifluoride is used for restraining the corrosion of magnesium in the baths. Sodium iodate also acts as a solution stabilizer and brightening agent. To use basic nickel carbonate as main salt under neutral bath system, samples were plated for $1 \mathrm{~h}$ at temperatures $60,70,80$ and $90^{\circ} \mathrm{C}$, respectively.

Table 1. Composition and operating conditions of Ni-W-P plating bath.

\begin{tabular}{lc}
\hline Plating bath composition & Concentration $\left(\mathrm{g} \mathrm{l}^{-1}\right)$ \\
\hline $\mathrm{Ni}\left(\mathrm{CH}_{3} \mathrm{COO}\right)_{2} \cdot 4 \mathrm{H}_{2} \mathrm{O}$ & 24 \\
$\mathrm{NaH}_{2} \mathrm{PO}_{2} \cdot \mathrm{H}_{2} \mathrm{O}$ & 24 \\
$\mathrm{Na}_{2} \mathrm{WO}_{4} \cdot 2 \mathrm{H}_{2} \mathrm{O}$ & 20 \\
$\mathrm{C}_{6} \mathrm{H}_{8} \mathrm{O}_{7}$ & 10 \\
$\mathrm{NH}_{4} \mathrm{HF}_{2}$ & 10 \\
$\mathrm{NaIO}_{3}$ & 0.002 \\
Operating conditions & 6.5 \\
pH & $85 \pm 2$ \\
Temperature $\left({ }^{\circ} \mathrm{C}\right)$ & \\
\hline
\end{tabular}

Coating surface and cross-section morphology are observed by scanning electron microscopy (SEM, HITACHI S-4800, Japan Hitachi), and energy dispersive X-ray spectroscopy EDS (INC250) to measure the content of $\mathrm{W}$ and $\mathrm{P}$.

The polarization curves of the NiWP alloy coatings were measured by using CHI660A (Shanghai Chenhua Instruments) electrochemistry workstation. Three-electrode cell was used with a platinum counter electrode and two saturated calomel reference electrodes. Specimens in the experiments were immersed in $3.5 \% \mathrm{NaCl}$ solution for $10 \mathrm{~min}$. When the open-circuit potentials became steady, the potentiodynamic polarization curves were measured at room temperature and the potential sweep rate was adjusted to $0.5 \mathrm{mv} \mathrm{s}^{-1}$.

\section{Results and discussion}

\subsection{Effect of plating temperature on surface morphology}

Figure 1 shows the surface morphology of NiWP alloy coating at temperatures from 60 to $90^{\circ} \mathrm{C}$. The NiWP coating shows spherical nodular structure varied with different temperatures. At temperature of $60^{\circ} \mathrm{C}$, an uneven surface morphology of the coatings prepared by electroless plating is observed by SEM (figure 1a). A possible explanation is that the deposition rate of nickel is very slow at $60^{\circ} \mathrm{C}$, high active parts prone to nickel nucleation, resulting in the formation of the spherical nodular structure.

The coating surface morphology become more compact at $70^{\circ} \mathrm{C}$ (figure $1 \mathrm{~b}$ ), and there is a obvious diameter fluctuation of the spherical nodular structure. The spherical nodular structure is more uniform and dense as the plating temperature reaches to $80^{\circ} \mathrm{C}$ (figure 1c). At $90^{\circ} \mathrm{C}$, the spherical nodular structure are uniform and dense and there exist many cracks (figure 1d). These cracks may be associated with the
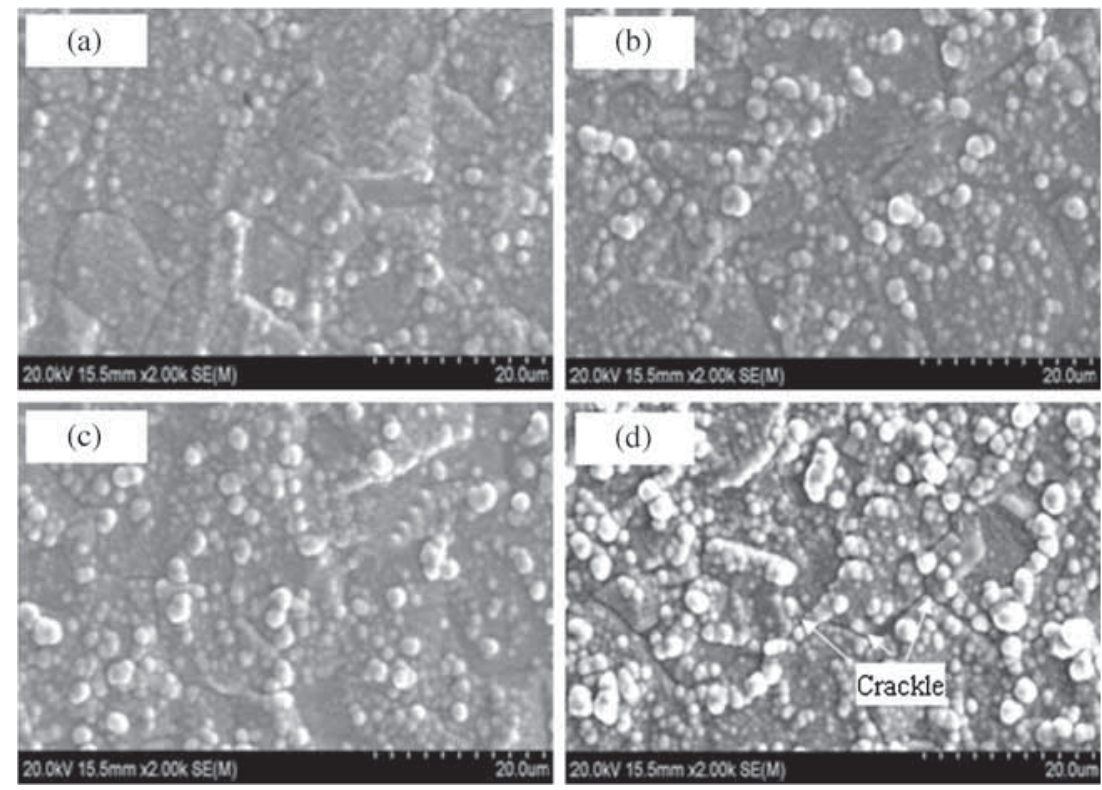

Figure 1. Surface morphology of NiWP alloy coating at temperatures from 60 to $90^{\circ} \mathrm{C}$ : (a) 60 , (b) 70, (c) 80 and (d) $90^{\circ} \mathrm{C}$. 
matrix inclusion and they were produced in the electroless plating process of hydrogen or the impurity particles induced in plating solution [19]. Comparing the coating surface morphologies at different temperatures, it can be seen that the higher the plating temperature, the more uniform, smooth and compact of the coating will be observed.

\subsection{Effect of plating temperature on particle sizes}

Average intercepts method was used to evaluate the effect of plating temperature on the particle sizes. Based on the calculation result of average spherical nodular diameter, shape factor $\zeta$ can be obtained by the following formula [20].

$$
\zeta=\frac{4 \pi A}{P^{2}}
$$

where $\zeta$ is shape factor, $P$ the length of the interface for spherical nodular $(\mu \mathrm{m}), A$ the cross-sectional area of grain $\left(\mu \mathrm{m}^{2}\right) . \zeta$ value varies between 0 and 1 . The more the $\zeta$ value means the more circular shape of the particles.

Figure 2 shows the diameter of cyathiform particles of coating surface in different plating temperatures. It can be seen that the higher the temperature, the smaller the diameter of cyathiform particles for NiWP coating.

Figure 3 is shape factor of cyathiform particles of coating surface in different plating temperatures. It can be seen that increase in the temperature will lead to the increase of the shape factor.

Catalytic effect can be used to explain the above results. A low temperature means a low deposition rate of nickel, i.e., the shape of cyathiform particles becomes more irregular with larger diameter at low temperature. As the temperature is increased, the more nickel catalytic core will be reduced at the same time in the electroless plating process. The nucleation of nickel core will be the main tendency and shape

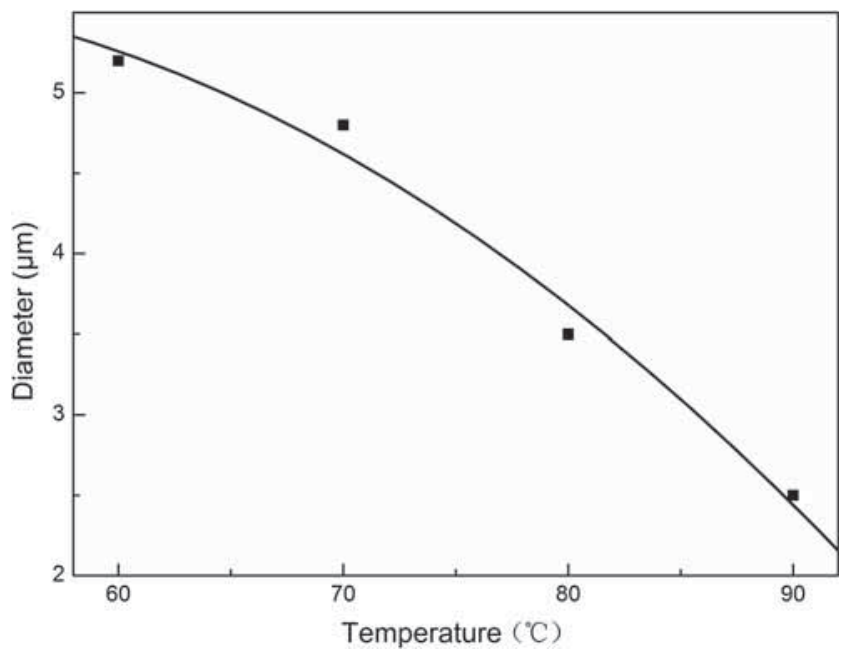

Figure 2. Relationship between plating temperature and diameter of cyathiform particles of NiWP coating. The cyathiform particles diameter decreases with the increase of the plating solution temperature.

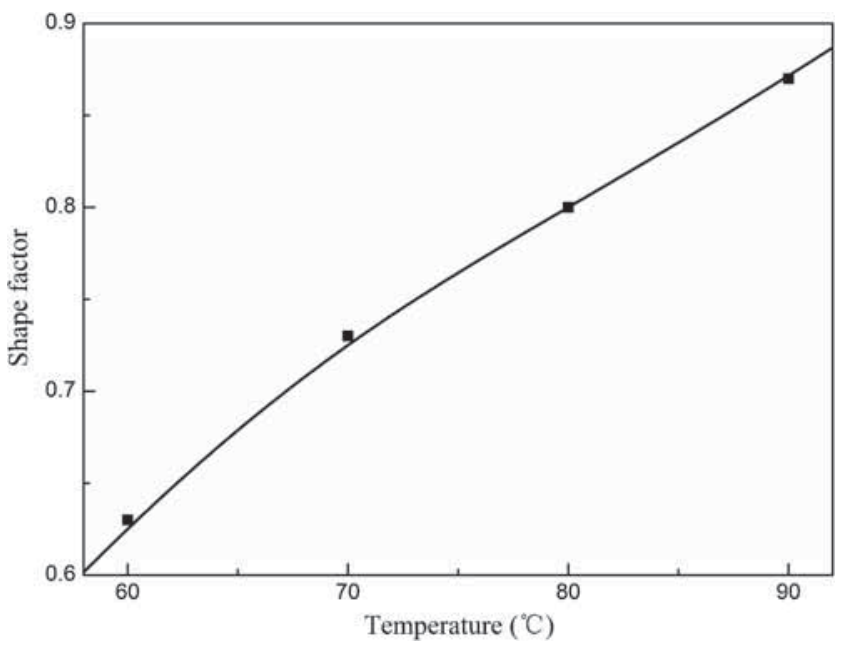

Figure 3. Relationship between temperature and shape factor of cyathiform particles of NiWP coating. The cyathiform particles shape factor increases with the increase in the plating solution temperature, and shape factor is close to 1 .

factor $\zeta$ will be increased, which will lead to form a small diameter of cyathiform particles [21].

\subsection{Effect of plating temperatures on coating thickness}

Figure 4 is the average thickness of NiWP coating as a function of plating temperature. It can be seen that the coating thickness increases linearly with an increase in plating temperature. According to electroless reaction mechanism, temperature plays a catalytic role for electroless plating. At a low temperature, there is a low dehydrogenation and oxidation of the reaction process, thus will lead to reduce the required electronic nickel deposition. However, with a high

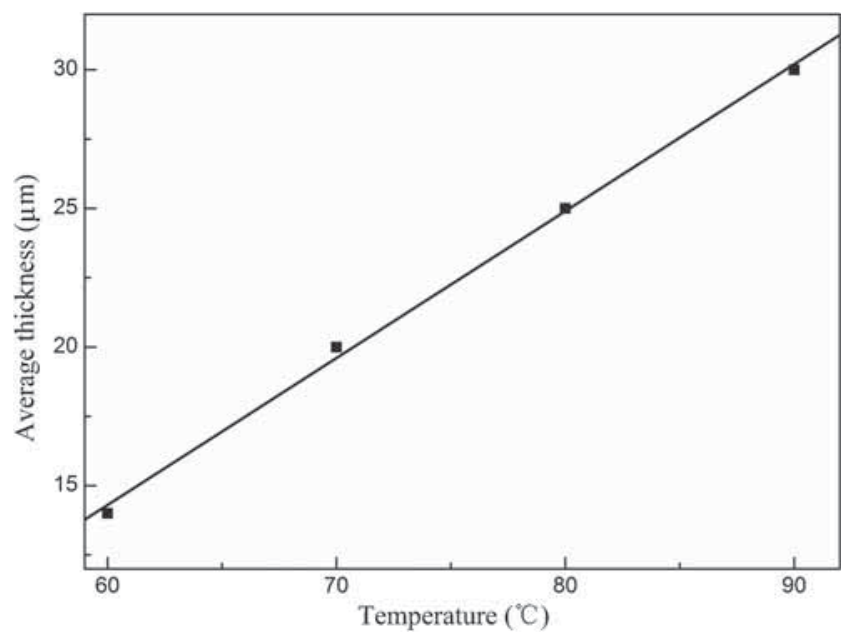

Figure 4. Average thickness of NiWP coating as a function of plating temperature. The average thickness of coating increases with the increase in the plating solution temperature. 


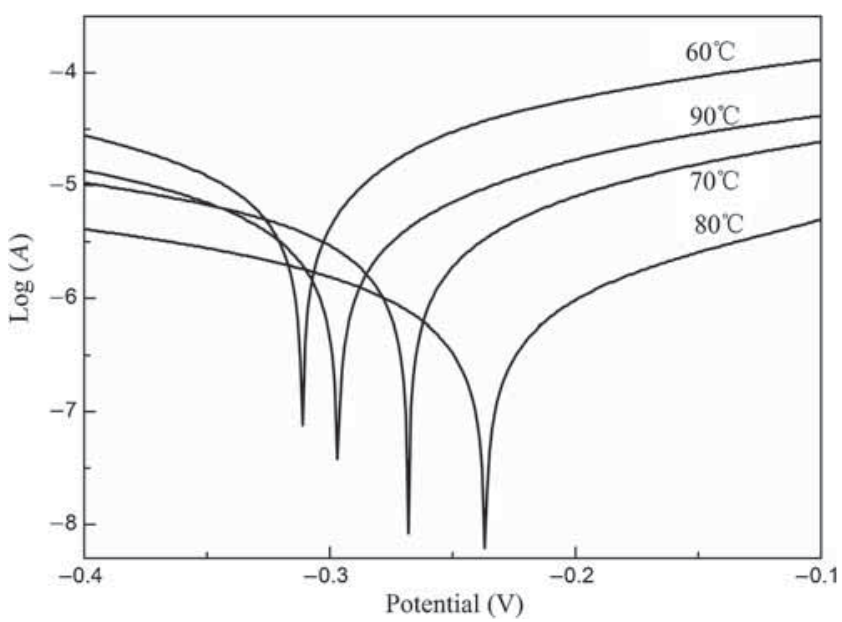

Figure 5. Polarization curves of the NiWP coatings under the temperature from 60 to $90^{\circ} \mathrm{C}$.

temperature, the dehydrogenation and oxidation process will be accelerated to form more electrons to meet the nickel deposition requirement, and thus to form a thickness of the coating [22].

According to EDS line scan on the cross-section, elements $\mathrm{W}, \mathrm{P}, \mathrm{Na}, \mathrm{F}$ and $\mathrm{C}$ mainly appeared in coating and substrate, while other elements appeared in the plating solution. Therefore, a sandwich layer structure of the coating is observed in this work. The possible reason may be that the pretreatment produced in the substrate surface membrane is not completely dissolved in the electroless plating process. Further, the generation in the substrate surface treatment before the film is not dense, leading to the solution into the matrix [23].

\subsection{Effect of plating temperatures on corrosion resistance of the coating}

Figure 5 shows the polarization curves of the NiWP coatings under different temperatures from 60 to $90^{\circ} \mathrm{C}$. Figure 6 is the relationship between the natural corrosion potential of the NiWP coatings in the $3.5 \% \mathrm{NaCl}$ solution and the plating solution temperatures from 60 to $90^{\circ} \mathrm{C}$.

It can be seen that with the increase in the plating temperature, from 60 to $80^{\circ} \mathrm{C}$, there is a sharp increase in natural corrosion potential. But with a further increase in temperature up to $90^{\circ} \mathrm{C}$, the natural corrosion potential will be decreased.

To explain the relationship between the natural corrosion potential and the plating solution temperatures from 60 to $90^{\circ} \mathrm{C}$, following consideration is proposed. At $60^{\circ} \mathrm{C}$, the coating is thin and not thick enough to protect the substrate, so the natural corrosion potential is low. As the temperature increases, the coating becomes more compact and uniform, which helps to form fine grain. At $80^{\circ} \mathrm{C}$, the natural corrosion potential reaches the maximum, and the coating has higher phosphorus content [24]. At $90^{\circ} \mathrm{C}$, although there is an increase of plating thickness and phosphorus content, the corrosion resistance becomes lower. Probably, there is

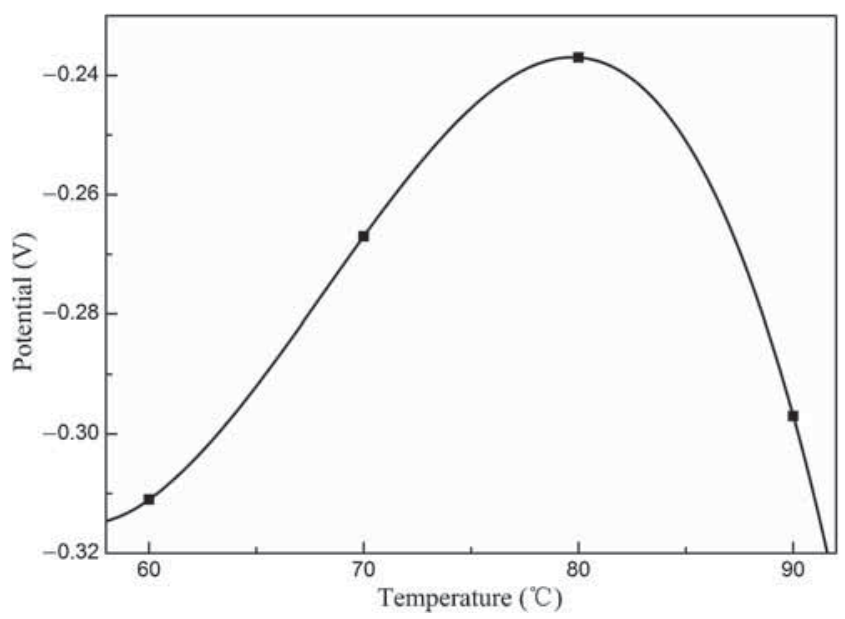

Figure 6. Relationship between temperature and the natural corrosion potential of NiWP coating in the $3.5 \% \mathrm{NaCl}$ solution. With the increase in the bath temperature, natural corrosion potential showed parabola change, increased first and then decreased, natural corrosion potential reached peak in $80^{\circ} \mathrm{C}$.

formation of the coating cracks and pores and the presence of a small amount of nickel within cracks and holes has been confirmed by EDS analysis. When the crack or hole at the bottom with less content of nickel has been corroded, the role of substrate and coating acts as battery corrosion in the electrolyte environment, substrate as anode and thus exacerbate the substrate corrosion.

\section{Conclusions}

(1) NiWP coating was deposited on AZ91D magnesium alloy by a basic nickel carbonate. The cyathiform particles diameter of coatings decreases with the increase in the plating solution temperature.

(2) At low temperature, the plating speed is slow, and the coating layer is relatively thin, rough and inhomogeneous. The plating speed increases with increase in the temperature, and the coating become more dense, uniform and thick. However, if the temperature exceeds $90^{\circ} \mathrm{C}$, the coating surface cracks will appear in the junction of substrate and coating surfaces.

(3) The varied temperature resulted in the change of structure and composition of the coating, leading to different coating corrosion resistances. At $80^{\circ} \mathrm{C}$, the coating's natural corrosion potential was moved to $-0.237 \mathrm{~V}$, with the best corrosion resistance.

\section{Acknowledgements}

Financial support from the State Key Laboratory of Metastable Materials Science and Technology Foundation. Research work in this paper is supported by China Scholarship Council. 


\section{References}

[1] Bulasara V K, Thakuria H, Uppaluri R and Purkait M K 2011 Desalination 268195

[2] Chen X M, Li G Y and Lian J S 2008 Trans. Nonferrous Met. Soc. China 18 s 323

[3] Selvi V E, Chatterji P, Subramanian S and Balaraju J N 2014 Surf. Coat. Technol. 240103

[4] Gu C C, Lian J S, He J G, Jiang Z H and Jiang Q 2006 Surf. Coat. Technol. 2005413

[5] Fini M H and Amadeh A 2013 Trans. Nonferrous Met. Soc. China 232914

[6] He F J, Fang Y Z and Jin S J 2014 Wear 31114

[7] Jin J, Liu C M, Fu S L, Gao Y R and Shu X 2011 Surf. Coat. Technol. 206348

[8] Lin C K, Hsu C H, Cheng Y H, Ou K L and Lee S L 2015 Appl. Surf. Sci. 32413

[9] Liu H, Guo R X, Zong Y, He B Q and Liu Z 2010 Trans. Nonferrous Met. Soc. China 201024

[10] Palaniappa M and Seshadri S K 2008 Wear 265735

[11] Shacham-Diamand Y, Osaka T, Okinaka Y, Sugiyama A and Dubin V 2015 Microelectron. Eng. 13235
[12] Shao Z C, Tian Y W and Li J Z 2006 Chinese J. Mater. Res. 20403

[13] Wang H, Chen Y N, Wei J F, Zhao Y Q and Qu K P 2009 Rare Metal Mater. Eng. 381533

[14] Liu H, Guo R X, Zong Y, He B Q and Liu Z 2010 Trans. Nonferrous Met. Soc. China 201024

[15] Yao H, Chang Q H and Wang X R 2010 Surf. Tech. 3926

[16] Wang T X, Meng J L and Hu Y J 2005 Surf. Tech. 3427

[17] Geng B S, Wei Y H, Hou L F, Li S, Yang H Y and Xu B S 2009 Rare Metal Mater. Eng. 3872

[18] Yao H, Chang Q H, Wang X R and Chen Y F 2010 Surf. Tech. 3961

[19] Wang Z C, Jia F, Yu L, Qi Z B, Tang Y and Song G L 2012 Surf. Coat. Technol. 2063676

[20] Zhao H, Huang Z H and Cui J Z 2008 J. Mater. Process. Technol. 203310

[21] Zhao M, Wu S S, Luo J R, Fukud Y and Nakae H 2006 Surf. Coat. Technol. 2005407

[22] Zhang W X, Huang N, He J G, Jiang Z H, Jiang Q and Lian J S 2007 Appl. Surf. Sci. 2535116

[23] Zhang W X, Jiang Z H, Li G Y and Jiang Q 2008 Surf. Coat. Technol. 2022570

[24] Zhong C, Liu F, Wu Y T, Le J J, Liu L, He M F, Zhu J C and Hu W B 2012 J. Alloys Compd. 52011 